\title{
The Test of the Efficiency of the Saudi Financial Capital Markets at Weak Form: An Empirical Study of the TASI Index and Sub-Indices of the Saudi Market
}

\author{
Tharwah Shaalan ${ }^{1}$ \\ ${ }^{1}$ Assistant professor, Business Administration faculty, Finance and Economics Department, Taibah University, KSA \\ Correspondence: Tharwah Shaalan, Assistant professor, Business Administration faculty, Finance and Economics \\ Department, Taibah University, KSA. Tel: 966-014-861-8888-4533. E-mail: tshaalan@taibahu.edu.sa
}

Received: December 2, 2018

Accepted: December 21, 2018

Online Published: February 7, 2019

doi:10.5430/afr.v8n1p183

URL: https://doi.org/10.5430/afr.v8n1p183

\begin{abstract}
The aim of this paper is to examine the normality of the destitution of the main Saudi TASI Index and the other sub-indices, as well as to test the random walk hypotheses of the Saudi TASI index and the random walk hypotheses of the main sectors index and the sub-indices in Saudi capital market. It investigates the weak form efficiency of the Saudi capital market. The study highlights the importance of structuring in the Saudi market, with regard to the redistribution of some companies in other sectors, in addition to the increase in the number of companies listed in the Saudi Tadawul market, where the study included larger and longer sectors in terms of the time period. An as extension, it requests the reconsideration of some previous studies, some of which proved the efficiency of the Saudi market and others which proved the inefficiency of the Saudi market at the level of low efficiency. The study test includes daily indices return from December 2002-October 2010. The results show that return series of all Saudi market indices have non-normal distribution. This paper applied four tests to examine the study's hypotheses. The Shapiro Wilk test of normality of the Skewness/Kurtosis applied and the other tests for RWH Box-Ljung, the other test one is parametric test Augmented Dicky-Fuller test and the other test is non-parametric test Phillips-Perron test and Run test. The result that was found states that the Saudi market's indices are inefficient in the weak form hypotheses.
\end{abstract}

Keywords: capital market, indices, RWH, weak form efficiency, unit roots

JEL: C22, E44, N25

\section{Introduction}

The investor recognizes the trends in the prices of securities through what is known as market indices or market averages. Market indicators reflect the trends in the prices of shares traded on the stock exchange based on the average prices of shares traded on the stock exchange at a certain time. These indicators change throughout the day if there is buying and selling throughout the day. In this case, the last prices to reach the shares is called the closing price. The prices are approved in the study because of all the daily changes in prices.

Kendall (1953) shows that markets in which the price of instruments fluctuates at random over their acceptable natural value, which in turn rationally reflects all information available to all parties appropriately, and which are quickly adjusted according to new information. It is important to note that the model, despite its emergence through a statistical study, indicates that its application is based on a logical deductive approach based on two objectives focused on the axis - the analysis of the financial instruments and thus to clarify how to build the investment portfolio, and by adopting this method, the model results in the conclusion that no one can accurately predict and agree with the short movements of the prices of the traded instruments.

\section{Literature Review}

The idea of the random movement of prices is referred to in French, Bachelier (1900) in his Ph.D. dissertation. The efficient market, according to Fama (1991), is the one that reflects Brealey at any time and fully in all available information, as long as all good information is available and it includes what is offered and what is appropriate to offer to securities. 
Several studies have been conducted to test the efficiency of financial markets and most of these studies have dealt with the efficiency of pricing and especially, efficiency at the weak level; one of the most famous of which was the study of the Fama (1965) through which he measured the random prices of the 30 shares registered with the Dow for five years between 1956 and 1961; the correlation coefficient between changes in the logarithm of stock prices was calculated at a time gap of one to ten days and the result of the measurement was that correlation coefficients were close to zero in most cases (about 0.03) and were less the greater the time interval used. The result confirms the random movement of stock prices, and therefore no investor can rely on past prices to create a strategy through which to achieve unjustified profits.

Fama (1970) expressed that there are three forms of proficient markets expressed and that there are three forms of productive markets.

\section{Imperial Literature}

One of the first and most important studies about market efficiency at the weak level was the study of Fama (1965), which tested the independence, repetitions and degree of natural distribution of daily changes in the shares of 30 companies registered with the Dow for the period 1956-1961. The study found that changes in stock prices followed normal distribution, that they were independent, not repetitive, and that stock prices were moving randomly and unpredictably.

The weak market efficiency formula states that prices reflect historical or prior information about the full price of securities related to the change in previous trading volume and the previous financial performance of issuers, which means prices cannot be predicted based on the information available in the past, since successive price changes are independent, known as the random walk theory of stock prices. Under this information, the financial investor cannot make extraordinary profits that exceed the average market rate of return covers and all risks associated with it, because all available information has been reflected in the prices of securities.

Keim and Stambaugh (1986) found great predictability in stock prices using forecasts based on predetermined variables. Fama and the French (1988) show that long-term retention revenues are highly negatively correlated, which means that $25-40 \%$ of the variance in horizon yields is more predictable than previous returns.

There are divergent views on the efficiency of stock markets and one of the most controversial issues in Capital Market Literature. Worthington and Higgs (2005) tested weak market efficiency in five emerging and emerging markets in Asia and the Pacific based on sequential and operational testing, concluding that all markets were ineffective. In the same research, the results of the contrast ratio test indicate that emerging markets are not compatible with random walking standards, whereas in developed country markets, there are only effective markets in Hong Kong, Shaikh and Nourine (2012) WF-EMH for the UK stock market. They believed that UK fund managers could not predict future stock behavior. Their findings were based on month-to-month returns data from $50 \mathrm{UK}$ investment funds over time (1990-2008) paper. The inefficiencies in the weak form of three advanced and five emerging economies are supported by Mishra (2011) who studied the application of RWH in these economies. It was noted that these economies had not followed a weak form efficiency. However, these shortcomings were associated with innovations and financial products and found that markets had become efficient in the long term.

Maghayereh (2003) the aim of his study was to test the impact of equity returns and January's effects on the Amman Stock Exchange (ASE), the period 1994-2002. GARCH and exponential GARCH (EGARCH) were applied for data analysis. The results showed strong evidence of a lack of seasonality on the ASE. Therefore, the results reached that the Amman market is an effective market.

Nisar, FCMA (2012) tested the RWH in the exchange markets in the Southeast Asia for a period of 14 years and found that the Asian markets were stationary.

Al-Khazali et al (2007) re-examined the empirical robustness of the weak-form efficiency in emerging markets of the MENA region: Bahrain, Egypt, Jordan, Kuwait, Morocco, Oman, Saudi Arabia and Tunisia. In their paper, they utilized the Lo and Mackinlay (1988, 1989), Wright's (2000) membership and sign VR and the runs tests. Once the returns from the indices were adjusted to reconcile twisting from thinly and infrequently traded stocks, the study found random walk weak-form efficiency in all the markets examined. Using multiple variance tests on different sectors, Benjelloun and Squali (2008) tested the markets of Jordan, Qatar, Saudi Arabia and the UAE and found that there is consistence in their result among the different sectors and the different markets, In contrast to most of the studies applied to emerging markets, the Haney and Greier Study (2012), which tested the efficiency of financial capital in Morocco and Kuwait at the weak level for the period 2008-2010, and the application of the Dickie Fuller Test, the Kapp's test and the Philips Byron Test, found that the results indicate that the indices of the Kuwait market and 
Morocco track random traffic, which explains that the two markets are efficient at a weak level. These results are consistent with the findings of Butler and Malaikah, (1992), who find significant correlation in stock markets in Kuwait and Saudi Arabia.

Khan Study on Pakistan market index (2016) reached that the daily and weekly returns were efficient while the monthly returns were inefficient.

In another study to test the efficiency of the Pakistan market index the results of Habiba, Ghumro, Ali Mirani (2017) suggested that, stock prices do not fully reflect previous information and the investor can defeat the market using previous information and can earn extraordinary profits. The results also indicate that previous prices for Pakistani equities affect future prices of equities showing non-random stock behavior. AL zeera and Asiri study (2013) which, test the Tadawul Saudi Index efficiency using daily returns proved that, the Saudi market index was efficient. In a test of stock markets in Latin America), Urrutia (1995) sees that these markets generally fail to pass weak form efficiency tests in that they do not follow random walking. However, it is seen as a weak form effective through the test runs, which means that investors are unlikely to be able to develop trading strategies to earn excess returns.

Unlike most of the previous studies, Bo Khalid's study conducted on the Dow Jones index (study) tested the efficiency of New York financial market at a weak level in Dow Jones Case study from 1924-2014 and proved that Dow Jones Index returns was efficient at a weak form level.

For the American markets Al-Magali's study (2015) results of Financial Times and Nasdaq indices indicated that randomization has been widely supported for both markets. However, the results of the correlation test were mixed, as RWH was supported for Nasdaq 100, while refuting the FTSE. The testing of special development services was the only way to strongly reject RWH for both indicators.

The method of calculating the Saudi Tadawul market index is as follows:

$$
\mathrm{R}_{\mathrm{it}}=\left[\left(\mathrm{I}_{\mathrm{it}}-/ \mathrm{I}_{\mathrm{it}-1}\right) / \mathrm{I}_{\mathrm{it}-1}\right] \times 100
$$

$\mathrm{R}_{\mathrm{it}}=$ the daily return on day $\mathrm{t}$ for sector $i$

$\mathrm{I}_{\mathrm{it}}:=$ stock index closing value for sector $i$

$\mathrm{I}_{\mathrm{it}-1}=$ stock index closing value for sector $i$ on day $\mathrm{t}-1$

The random walk equation

$$
\mathrm{R}_{1}=\mathrm{R}_{\mathrm{o}}+\sum_{j=1}^{t} u j
$$

Where $R_{t}$ is the stock return at time $t$ and $P_{0}$ is the initial stock return

\section{Data and Methodology}

\subsection{Sample and Analyzing Data}

The Stata V.14 used daily data from 01/10/2007-01/10/ 2018 of TASI and other indicators Indices to run all study test, using the time series tests. The study society are twenty one with TASI, the sub-indicators are twenty, the study sample is seventeen indicators, while four indicators eliminated because of unavailability of the data for the same period of study (Health Sector, Multi-Investment Sector, Professional Services Sector, Medicines Sector), see Table (1) in appendix (Note 1).

\subsection{The Study Hypothesizes}

$\mathrm{H}_{1}$ : The daily returns of the Saudi stock indices are normally distributed

$\mathrm{H}_{2}: \Upsilon=1$. The test of this hypothesis is a unit root exists and that means $Y$ nonstationary and has random walk

$\mathrm{H}_{3:} \rho=0$. The All correlation coefficients $=0$, and that is mean the $\mathrm{Y}$ nonstationary and has random walk.

$\mathrm{H}_{4}$ : The time series are random

Most Authors and scientists used a Skewness and a Kurtosis statistic to examine the symmetric of the time series data, Skewness has also been defined with respect to the third moment about the mean:

$$
\gamma_{1}=\frac{\sum(Y-\mu)^{3}}{n \sigma^{3}}
$$

which is simply the expected value of the distribution of cubed $z$ scores. Skewness measured in this way is sometimes referred to as "Fisher's skewness." When the deviations from the mean are greater in one direction than in the other direction, this statistic will deviate from zero in the direction of the larger deviations. FFrom sample data, Fisher's skewness is most often estimated by: 


$$
g_{1}=\frac{n \sum z^{3}}{(n-1)(n-2)}
$$

For large sample sizes $(n>150), g_{l}$ may be distributed approximately normally, with a standard error of approximately $\sqrt{6 / n}$. While one could use this sampling distribution to construct confidence intervals for or tests of hypotheses about $\gamma_{1}$, there is rarely any value in doing so.

Karl Pearson (1905) defined a distribution's degree of kurtosis as $\eta=\beta_{2}-3$, where

$$
\beta_{2}=\frac{\sum(Y-\mu)^{4}}{n \sigma^{4}}
$$

the expected value of the distribution of $Z$ scores which have been raised to the $4^{\text {th }}$ power. $\beta_{2}$ is often referred to as "Pearson's kurtosis," and $\beta_{2}-3$ (often symbolized with $\gamma_{2}$ ) as "kurtosis excess" or "Fisher's kurtosis" even though it was Pearson who defined kurtosis as $\beta_{2}-3$. An unbiased estimator for $\gamma_{2}$ is:

$$
g_{2}=\frac{n(n+1) \sum Z^{4}}{(n-1)(n-2)(n-3)}-\frac{3(n-1)^{2}}{(n-2)(n-3)}
$$

For large sample sizes ( $\mathrm{n}>1000)$, g2 may be distributed approximately normally, with a standard error of approximately $\sqrt{24 / n}$ (Snedecor, \& Cochran, 1967). While one could use this sampling distribution to construct confidence intervals for or tests of hypotheses about $\gamma 2$, there is rarely any value in doing so.

If $\gamma 1=0$ the skewness is un asymmetric distributed and $\gamma_{2}<3$, the kurtosis also is un asymmetrically distributed.

\section{Empirical Result}

\section{The first hypotheses test}

The Shapiro Wilk test used of normality of the Skewness/Kurtosis, statistically the test result proved that, the time series foe all indicators indices are not symmetric, the probability chi $^{2}$ Skewness/Kurtosis tests for normality are summarized in Table 1 are significant at (0.01), also the histogram of the normality distribution showed in the appendix (Note 1) figures for the all indicators indices (1-17). Most indicators-histograms showed a skewness toward the right side, which reflected the investors interests in returns in those sectors. In contrast, five torsion

\begin{tabular}{|c|c|c|c|c|c|c|c|}
\hline $\mathbf{N}$ & Indicators & Mean & $\begin{array}{l}\text { Standard } \\
\text { deviation }\end{array}$ & Skewness & Kurtosis. & $\begin{array}{c}\text { Kurtosis } \\
\text { Skewness/ } \\
\text { Prob>chi2 tests for } \\
\text { Normality }\end{array}$ & Decision \\
\hline 1 & TASI & 0.00014 & 0.0107 & $-0.563 * * *$ & $14.28 * * *$ & 0.0000 & Reject $\mathrm{H}_{0}$ \\
\hline 2 & TBNI & -0.00017 & 0.0189 & $-23.16^{* * *}$ & $839.7 * * *$ & 0.0000 & Reject $\mathbf{H}_{0}$ \\
\hline 3 & TCGI & -0.00004 & 0.0154 & $-2.503 * * *$ & $38.36 * * *$ & 0.0000 & Reject $\mathbf{H}_{0}$ \\
\hline 4 & TCSI & 0.00002 & 0.0211 & $6.38 * * *$ & $147.83^{* * * *}$ & 0.0000 & Reject $\mathbf{H}_{0}$ \\
\hline 5 & TDAI & 0.00042 & 0.0356 & $34.69 * * *$ & $1436.66^{* * *}$ & 0.0000 & Reject $\mathbf{H}_{0}$ \\
\hline 6 & TENI & 0.00004 & 0.0141 & $-0.336^{* * *}$ & $10.945^{* * *}$ & 0.0000 & Reject $\mathbf{H}_{0}$ \\
\hline 7 & TFBI & 0.00016 & 0.0244 & $4.234 * * *$ & $139.48 * * *$ & 0.0000 & Reject $\mathbf{H}_{0}$ \\
\hline 8 & TFSI & -0.00003 & 0.0165 & $-7.04 * * *$ & $185.58^{* * *}$ & 0.0000 & Reject $\mathbf{H}_{0}$ \\
\hline 9 & TISI & 0.00152 & 0.053 & $29.85 * * *$ & $1169.78 * * *$ & 0.0000 & Reject $\mathbf{H}_{0}$ \\
\hline 10 & TMDI & 0.00145 & 0.032 & $11.37 * * *$ & $315.48 * * *$ & 0.0000 & Reject $\mathbf{H}_{0}$ \\
\hline 11 & TMTI & 0.00020 & 0.011 & $0.633 * * *$ & $24.795^{* * *}$ & 0.0000 & Reject $\mathbf{H}_{0}$ \\
\hline 12 & TRLI & 0.00028 & 0.016 & $-14.76^{* * *}$ & $455.56^{* * *}$ & 0.0000 & Reject $\mathbf{H}_{0}$ \\
\hline 13 & TRMI & 0.00021 & 0.016 & -3.625 & $71.74 * * *$ & 0.0000 & Reject $\mathbf{H}_{0}$ \\
\hline 14 & TRTI & 0.00049 & 0.023 & $16.14 * * *$ & $525.43^{* * *}$ & 0.0000 & Reject $\mathbf{H}_{0}$ \\
\hline 15 & TTNI & 000241 & 0.017 & $-5.121 * * *$ & $105.89 * * *$ & 0.0000 & Reject $\mathbf{H}_{0}$ \\
\hline 16 & TTSI & 0.0010 & 0.048 & $40.39 * * *$ & $1753.83 * * *$ & 0.0000 & Reject $\mathbf{H}_{0}$ \\
\hline 17 & TUTI & 0.0003 & 0.016 & $7.04 * * *$ & $185.58 * * *$ & 0.0000 & Reject $\mathbf{H}_{0}$ \\
\hline
\end{tabular}
indicators showed skewness towards the left side (TMDI, TRTI, TTSI, TDNI, TISII).

Table 1. Descriptive analysis \& Shapiro Wilk test of normality skewness/kkurtosis

$* * * \mathrm{P}<0.01$ 


\section{The Augmented Dickey Fuller Model}

The Augmented Dickey Fuller adds lagged differences to these models:

No constant, no trend: $\Delta \mathrm{y}_{\mathrm{t}}=\gamma \mathrm{y}_{\mathrm{t}-1}+\overline{s=1} \mathrm{a}_{\mathrm{s}} \Delta \mathrm{y}_{\mathrm{t}-\mathrm{s}}+v_{\mathrm{t}}$

Constant, no trend: $\Delta \mathrm{y}_{\mathrm{t}}=\alpha+\gamma \mathrm{y}_{\mathrm{t}-1}+\overline{s=1} \mathrm{a}_{\mathrm{s}} \Delta \mathrm{y}_{\mathrm{t}-\mathrm{s}}+v_{\mathrm{t}}$

Constant and trend: $\Delta \mathrm{y}_{\mathrm{t}}=\alpha+\gamma \mathrm{y}_{\mathrm{t}-1}+\lambda_{\mathrm{t}}+\overline{s=1} \mathrm{a}_{\mathrm{s}} \Delta \mathrm{y}_{\mathrm{t}-\mathrm{s}}+v_{\mathrm{t}}$

$\Upsilon$ coefficient of $\mathrm{R}$ and $\mathrm{R}_{\mathrm{t}-1}$ the return with difference lag $1, \varepsilon_{\mathrm{t}}$ is a white noise.

\section{PHILLIPS-PERRON}

Phillips and Peron (1988) have developed a more comprehensive theory of unit root nonstationary. The tests are similar to ADF tests. The Phillips-Perron (PP) unit root tests is non-parametric test and differ from the ADF tests mainly in how they deal with serial correlation and heteroskedasticity in the errors. These modified statistics, denoted $\mathrm{Zt}$ and $\mathrm{Z} \delta$, are given by

$$
\begin{aligned}
& z_{t}=\sqrt{\frac{\hat{\sigma}^{2}}{\hat{\lambda}^{2}}}{ }_{\delta}-\frac{1}{2}\left(\frac{\hat{\lambda}^{2}-\hat{\sigma}^{2}}{\hat{\lambda}^{2}}\right)\left(\frac{n(\sec (\hat{\sigma}))}{\hat{\sigma}^{2}}\right) \\
& z_{s}=n \hat{s}-\frac{1}{2} \frac{n^{2}(s \cdot c \cdot(\hat{s}))}{\hat{\sigma}^{2}}\left(\hat{x}^{2}-\hat{\sigma}^{2}\right)
\end{aligned}
$$

The terms $\hat{\boldsymbol{O}}^{2}$ and $\hat{\boldsymbol{Z}}$ are consistent estimates of the variance parameters

$$
\sigma^{2}=\lim _{n \leftarrow \infty} n^{-1} \sum_{t=1}^{n} E\left(a_{t}^{2}\right)
$$

$\lambda^{2}=\lim _{n \rightarrow \infty} \sum_{t=1}^{n} E\left(\frac{1}{n} \sum_{t=1}^{n} a_{t}^{2}\right)$

\section{The second hypotheses test:}

The table (2) summarized the ADF and PP test after confederation of lags determination using Shwartz information criteria, most of indicators were stationary at the lage $(0,1)$, exept three indices (TFBI, TMDI, TMTI) were staionary at lag (2). Also all ADF models were without conestants and trends.aslo the culculated ADF and PP test is higher than the tabulated ADF and PP test at significance level of 0.01 .

Table 2. Shwartz information lag criteria \&Test Model

\begin{tabular}{ll}
\hline TASI & $\mathbf{1}$ \\
\hline TBNI & 1 \\
\hline TCGI & 1 \\
\hline TCSI & 1 \\
\hline TDAI & 0 \\
\hline TENI & 1 \\
\hline TFBI & 2 \\
\hline TFSI & 0 \\
\hline TISII & 1 \\
\hline TMDI & 2 \\
\hline TMTI & 2 \\
\hline TRLI & 1 \\
\hline TRMI & 1 \\
\hline TRTI & 0 \\
\hline TTNI & 1 \\
\hline TTSI & 0 \\
\hline TUTI & 1
\end{tabular}

\section{Without trend and intercept}


Table 3. ADF, PP test

\begin{tabular}{ccccc}
\hline Indicators & Augmented Dickey- Fuller t-statistic & Phillips - Perron t-statistic \\
\hline TASI & Results & Decision & Results & Decision \\
TBNI & $-30.22 * * *$ & Reject $\mathrm{H}_{0}$ & $-39.82 * * *$ & Reject $\mathrm{H}_{0}$ \\
TCGI & $-30.59 * * *$ & Reject $\mathrm{H}_{0}$ & $-43.01 * * *$ & Reject $\mathrm{H}_{0}$ \\
TCSI & $-31.24 * * *$ & Reject $\mathrm{H}_{0}$ & $-40.94 * * *$ & Reject $\mathrm{H}_{0}$ \\
TDAI & $-29.73 * * *$ & Reject $\mathrm{H}_{0}$ & $-39.68 * * *$ & Reject $\mathrm{H}_{0}$ \\
TENI & $-43.91 * * *$ & Reject $\mathrm{H}_{0}$ & $-43.91 * * *$ & Reject $\mathrm{H}_{0}$ \\
TFBI & $-30.01 * * *$ & Reject $\mathrm{H}_{0}$ & $-41.24 * * *$ & Reject $\mathrm{H}_{0}$ \\
TFSI & $-30.68 * * *$ & Reject $\mathrm{H}_{0}$ & $-56.90 * * *$ & Reject $\mathrm{H}_{0}$ \\
TISII & $-42.47 * * *$ & Reject $\mathrm{H}_{0}$ & $-42.47 * * *$ & Reject $\mathrm{H}_{0}$ \\
TMDI & $-44.95 * * *$ & Reject $\mathrm{H}_{0}$ & $-42.18^{* * * *}$ & Reject $\mathrm{H}_{0}$ \\
TMTI & $-25.92 * * *$ & Reject $\mathrm{H}_{0}$ & $-42.48 * * *$ & Reject $\mathrm{H}_{0}$ \\
TRLI & $-23.97 * * *$ & Reject $\mathrm{H}_{0}$ & $-40.27 * * *$ & Reject $\mathrm{H}_{0}$ \\
TRMI & $-29.87 * * *$ & Reject $\mathrm{H}_{0}$ & $-42.08 * * *$ & Reject $\mathrm{H}_{0}$ \\
TRTI & $-30.37 * * *$ & Reject $\mathrm{H}_{0}$ & $-40.99 * * *$ & Reject $\mathrm{H}_{0}$ \\
TTNI & $-43.01 * * *$ & Reject $\mathrm{H}_{0}$ & $-43.01 * * * *$ & Reject $\mathrm{H}_{0}$ \\
TTSI & $-30.54 * * *$ & Reject $\mathrm{H}_{0}$ & $-41.72 * * *$ & Reject $\mathrm{H}_{0}$ \\
TUTI & $-44.95 * * *$ & Reject $\mathrm{H}_{0}$ & $-44.95^{* * *}$ & Reject $\mathrm{H}_{0}$ \\
TASI & $-30.49 * * *$ & Reject $\mathrm{H}_{0}$ & $-42.47 * * *$ & Reject $\mathrm{H}_{0}$ \\
\hline
\end{tabular}

$* * * \mathrm{P}<0.01$

\section{Box-Ljung}

In large samples, if $\rho_{k}=0$ for all $k \leq m$, then

$$
L B=n(n+2) \sum_{k=1}^{m}\left(\frac{\widehat{\rho}_{k}^{2}}{n-k}\right) \sim \chi_{m}^{2}
$$

A way to check randomness in the data Lag 0 of the autocorrelation is 1 by definition

i. If the autocorrelation dies out slowly, this indicates that the process is non-stationary.

ii. If all the ACFs are close to zero, then the series should be considered white noise.

If $\mathrm{Q}>\mathrm{X}^{2}$ then we reject $\mathrm{H}_{0}$ and accept the alternative hypotheses that provides that the time series is stationary.

\section{The third hypotheses test:}

The Box-Pierce results showed that, all indices (the main index TASI and the other sub-indices) not correlated with their returns in the previous periods, with high levels of significance at (0.01) and the calculated Q-statistic is greater than the table Q-statistic with more than ten lags. This result confirmed that the majority of those indices were not efficient at the weak form level and confirmed also that there had not trend because of the positive and negative auto correlation in the time series returns, as they showed in the indices and tables that some indices where their calculated Q-statistic were less than the table Q-statistic (TBNI, TADI, TTSI) and were not significant at $(0.05)$ as showed in Tables $(10,14,17)$ and autocorrelation Figures $(7,11,14)$ in the appendix (Note 1$)$. 
Table 4. Portmanteau test for white noise

\begin{tabular}{lccl}
\hline \multirow{2}{*}{ Indexes } & \multicolumn{2}{c}{ Portmanteau test for white noise } & \\
\cline { 2 - 3 } & Portmanteau $(\mathrm{Q})$ statistic & Prob $>$ hi2(10) & \\
\hline TASI & 31.057 & 0.0000 & \\
TMDI & 47.145 & 0.0000 & Reject $\mathrm{H}_{0}$ \\
TENI & 34.319 & 0.0000 & Reject $\mathrm{H}_{0}$ \\
TISII & 26.9032 & 0.0131 & Reject $\mathrm{H}_{0}$ \\
TCSI & 48.118 & 0.0027 & Reject $\mathrm{H}_{0}$ \\
TCGI & 33.059 & 0.0003 & Reject $\mathrm{H}_{0}$ \\
TDAI & 5.1233 & 0.8828 & Reject $\mathrm{H}_{0}$ \\
TRTI & 18.340 & 0.0495 & Accept $\mathrm{H}_{0}$ \\
TFBI & 171.74 & 0.0000 & Reject $\mathrm{H}_{0}$ \\
TUTI & 22.933 & 0.0110 & Reject $\mathrm{H}_{0}$ \\
TBNI & 11.0311 & 0.3551 & Reject $\mathrm{H}_{0}$ \\
TFSI & 22.933 & 0.0110 & Accept $\mathrm{H}_{0}$ \\
TMTI & 37.135 & 0.0001 & Reject $\mathrm{H}_{0}$ \\
TTSI & 1.0402 & 0.9998 & Reject $\mathrm{H}_{0}$ \\
TRLI & 21.522 & 0.0177 & Accept $\mathrm{H}_{0}$ \\
TRMI & 23.892 & 0.0079 & Reject $\mathrm{H}_{0}$ \\
TTNI & 23.984 & 0.0076 & Reject $\mathrm{H}_{0}$ \\
\hline
\end{tabular}

\section{Run test}

Fama (1965) used the run test to examine the Random Walk Hypotheses, a run test is a series of consecutive negative returns (-) or positive (+) and its length is account of successive signs. It is a non-parametric test. And it was designed to check the random test of the series, especially those series are does not require any specific probability distribution.

This test is based on the understanding that if the series of random data, the number of actual occurrences in the chain must be close to the number of iterations expected repetition is defined as price variability with the same signal. Under random walk assumptions, actual value of runs and the expected value of runs are equal.

$\mathrm{N}=\mathrm{N}++\mathrm{N}$

Where $(\mathrm{N})$ is the total amount of runs; $(\mathrm{N}+)$ is the amount of positive runs; $(\mathrm{N}-)$ amount of negative runs. Consecutive runs are independent of each other under null hypothesis H0. The null hypothesis of randomness is rejected if Z-value is larger than or equal to $( \pm 1.96)$ at $95 \%$ level of significant.

\section{The fourth hypothesis test:}

The Run test results of the seventeen indices, the main one TASI and the sun-indicators proved that, all are not random walk series, al the results were significant at between $(0.01,0.05)$.As shown in table(5) 
Table 5. Run test Result

\begin{tabular}{lll}
\hline Indexes & \multicolumn{1}{c}{ Run test } & Decision \\
\hline TASI & $\mathrm{N}($ runs $)=888 ; \mathrm{z}=-5.56 ; \operatorname{Prob}>|\mathrm{z}|=0$ & Reject $\mathrm{H}_{0}$ \\
TMDI & $\mathrm{N}($ runs $)=968 ; \mathrm{z}=-1.98 ; \operatorname{Prob}>|\mathrm{z}|=.05$ & Reject $\mathrm{H}_{0}$ \\
TENI & $\mathrm{N}($ runs $)=956 ; \mathrm{z}=-2.51 ; \operatorname{Prob}>|\mathrm{z}|=.01$ & Reject $\mathrm{H}_{0}$ \\
TISII & $\mathrm{N}($ runs $)=924 ; \mathrm{z}=-3.94 ; \operatorname{Prob}>|\mathrm{z}|=0$ & Reject $\mathrm{H}_{0}$ \\
TCSI & $\mathrm{N}($ runs $)=936 ; \mathrm{z}=-3.4 ; \operatorname{Prob}>|\mathrm{z}|=0$ & Reject $\mathrm{H}_{0}$ \\
TCGI & $\mathrm{N}($ runs $)=914 ; \mathrm{z}=-4.38 ; \operatorname{Prob}>|\mathrm{z}|=0$ & Reject $\mathrm{H}_{0}$ \\
TDAI & $\mathrm{N}($ runs $)=906 ; \mathrm{z}=-4.74 ; \operatorname{Prob}>|\mathrm{z}|=0$ & Reject $\mathrm{H}_{0}$ \\
TRTI & $\mathrm{N}($ runs $)=966 ; \mathrm{z}=-2.07 ; \operatorname{Prob}>|\mathrm{z}|=.04$ & Reject $\mathrm{H}_{0}$ \\
TFBI & $\mathrm{N}($ runs $)=934 ; \mathrm{z}=-3.49 ; \operatorname{Prob}>|\mathrm{z}|=0$ & Reject $\mathrm{H}_{0}$ \\
TUTI & $\mathrm{N}($ runs $)=974 ; \mathrm{z}=-1.71 ; \operatorname{Prob}>|\mathrm{z}|=.05$ & Reject $\mathrm{H}_{0}$ \\
TBNI & $\mathrm{N}($ runs $)=908 ; \mathrm{z}=-4.65 ; \operatorname{Prob}>|\mathrm{z}|=0$ & Reject $\mathrm{H}_{0}$ \\
TFSI & $\mathrm{N}($ runs $)=966 ; \mathrm{z}=-2.07 ; \operatorname{Prob}>|\mathrm{z}|=.04$ & Reject $\mathrm{H}_{0}$ \\
TMTI & $\mathrm{N}($ runs $)=930 ; \mathrm{z}=-3.67 ; \operatorname{Prob}>|\mathrm{z}|=0$ & Reject $\mathrm{H}_{0}$ \\
TTSI & $\mathrm{N}($ runs $)=972 ; \mathrm{z}=-1.8 ; \operatorname{Prob}>|\mathrm{z}|=.04$ & Accept $\mathrm{H}_{0}$ \\
TRLI & $\mathrm{N}($ runs $)=914 ; \mathrm{z}=-4.38 ; \operatorname{Prob}>|\mathrm{z}|=0$ & Reject $\mathrm{H}_{0}$ \\
TRMI & $\mathrm{N}($ runs $)=930 ; \mathrm{z}=-3.66 ; \operatorname{Prob}>|\mathrm{z}|=0$ & Reject $\mathrm{H}_{0}$ \\
TTNI & $\mathrm{N}($ runs $)=938 ; \mathrm{z}=-3.31 ; \operatorname{Prob}>|\mathrm{z}|=0$ & Reject $\mathrm{H}_{0}$ \\
\hline
\end{tabular}

\section{Conclusion}

Our finding is very similar to the results of studies conducted in the Arab Region and Southeast Asia in terms of the inefficiency of these markets in terms of weak form, but they denied the results of a study which proved the efficiency of the main indicator as well as the efficiency of most of the indicators included in the study of a Alzeera and Asiri (2013).

The Fourth test Hypothesizes proved that all 17 indices for the Saudi Market which are traded were not fellow the random walk hypotheses. Banking and financial service sector, Telecom Sector, and Long-term goods Sector had no auto correlation as the Box-LJoung test results explained. This can be explained by the fact that these sectors have been affected by the US market crisis and there have been shocks within the yields of the indices. All parametric tests (the data normality test and ADF for the unit root) and non-parametric test (PP and Box-LJoung, and Run test) showed that, the Saudi market indices are not efficient at the weak form efficiency.

The study reached through the three tests that were take place: unit root tests including the test of the ADF test, which is parametric test and the other which is not parametric test of Philip Peron for the root of the argument, and the results of the two tests were quite identical which is the absence of the root of the unit, which proves the inefficiency of Saudi market indices, the main indicator TASI and other sub-indicators, as well .

The Auto correlation and partial auto correlation test proved that there are no links between returns over time with high significance level for most indicators, which confirms the inefficiency of the Saudi market at the weak level and that mean ,the investors can achieve abnormal returns from trading in Saudi Tadawul Market.

\section{Recommendation}

I recommend that researchers conduct more detailed tests of the index of the banking and financial services sector as well as the telecommunications sector and the long-term capital goods sector and conduct long-term market memory tests for these sectors.

\section{References}

Al-Khazali, O.M., et, all. (2007). A New Variance Ratio Test of Random Walk in Emerging Markets: A Revisit, The Financial Reivew, 42, 303-317. https://doi.org/10.1111/j.1540-6288.2007.00173.x 
Al-zeera, H. Asiri, B. (2013). Is the Saudi Market Efficient? A case of Weak -form efficiency, Research Journal of Finance and Accounting, 4(6), 35-48.

Bachelier, L. (2006). Theory of Speculation: Origins of Modern Finance. (M. Davis and A. Etheridge, Trans). Princeton, NJ: Princeton University Press. (original work published in 1900).

Benjelloun, H., Squalli, J. (2008). Do General Indices Mask Sectoral Efficiencies? A Multiple Variance Ratio Assessment of Middle Eastern Equity Markets, International Journal Of Managerial Finance, June, 136-151. https://doi.org/10.1108/17439130810864023

Butler, K.C., \& Malaikah, S.J. (1992). Efficiency and Inefficiency in Thinly Traded Stock Markets: Kuwait and Saudi Arabia, Journal of Banking and Finance, 16(2), 197-210. https://doi.org/10.1016/0378-4266(92)90085-E

Fama, E. (1965). The Behavior of stock Market Price. Journal of Business, 34-105. https://doi.org/10.1086/294743

Fama, E. F. (1970). Efficient capital markets: A review of theory and empirical work. The Journal of Finance, 25(2), 383-417. https://doi.org/10.2307/2325486

Fama, E.F., French, K. R. (1988). Permanent and Temporary Components of Stock Prices. Journal of Political Economics, 96(2), 246-273. https://doi.org/10.1086/261535

Fama, E.F. (1991). Efficient Capital Markets: II. The Journal of Finance, 46(5), 1575-1617. https://doi.org/10.1111/j.1540-6261.1991.tb04636.x

Haney, N. Gharayia, Z. (2012). Test the random traffic model of the stock price movement in the context of the efficiency of the financial markets in the emerging Arab stock exchanges-case study of the Morocco and Kuwait Stock Exchange. Economic and Administrative Research Journal, (11), 78-49.

Habibah, U., et, all. (2017). Testing the Random Walk. International Journal of Academic Research in Business and Social Sciences, 7(7), 1-15. https://doi.org/10.6007/IJARBSS/v7-i7/3121

Iqbal \& Mallika, T. (2007). Market Reaction to Earnings Information: An Empirical Study. Aims International, 1(2), $153-167$.

Lo, A.W., Mackinlay, A. C. (1988). Stock Market Prices Do Not Follow Random Walks: Evidence from a Simple Specification Test. The Review of Financial Studies, 1(1), (Spring 1988), 41-66.

Lo, A.W., Mackinlay, A. C. (1989). The size and power of variance ratio test in finite samples: a Monte Carlo investigation. Journal of Econometrics, 40, 203-38. https://doi.org/10.1016/0304-4076(89)90083-3

Khan,N, Akhtar,S. (2016). Weak Form of Efficient Market Hypothesis - Evidence from Pakistan. Journal of Asia Business Studies, 8, 1-18.

Kendall, M. G. (1953). The Analysis of Economic Time-Series Part I: Price. Journal of the Royal Statistical Society. A(General), Blackwell Publishing, (116) (1), 11-34. https://doi.org/10.2307/2980947

Keim, D. Stambaugh, R. (1986). Predicting Returns in the stock and Bond Markets. Journal of Financial Economics, 17, 357-390. https://doi.org/10.1016/0304-405X(86)90070-X

Maghayereh, A. (2003). Seasonality and January Effect Anomalies in an Emerging Capital Market. Working paper, College of Economics and Administrative Sciences, the Hashemite University, Zarqa, Jordan.

Mbululu, D., Auret, C.J., et, all. (2014). Do Exchange Rates Follow Random Walks? A Variance Ratio Test of the Zambian Foreign Exchange Market. Southern African Business Review, 17(2), 45-66.

Mishra, P. K. (2011). Weak form market efficiency: Evidence from emerging and developed world. The Journal of Commerce, 3(2), 26-34.

Nisar, S., FACMA, M. (2012). Testing Weak Form of Efficient Market Hypothesis: Empirical Evidence from South-Asia. World Applied Sciences Journal, 17(4), 414-427.

Pearson, K. (1905). Das Fehlergesetz und seine Verallgemeinerungen durch Fechner und Pearson. A Rejoinder. Biometrika, 4, 169-212. https://doi.org/10.2307/2331536

Phillips, P. Perron, P. (1988). Testing for a Unit Root in Time Series Regression, Biometrika, 75(2), 335-346. https://doi.org/10.1093/biomet/75.2.335

Snedecor, G.W. \& Cochran, W.G. (1967). Statistical methods (6th ed.), Iowa State University Press, Ames, Iowa.

Shumway, R.H, Stoffer, D.S. (2006). Time Series Analysis and Its Ap-plications. With R Examples. 2nd edition. 


\section{Springer.}

Urrutia, J.L. (1995). Tests of Random Walk Efficiency for Latin American Emerging Equity Markets. Journal of Financial Research, 18(3), 299-313. https://doi.org/10.1111/j.1475-6803.1995.tb00568.x

Worthington, A. Higgs, H. (2004). Random walks and market efficiency in European Equity Markets. Global Journal of Finance and Economics, 1(1), 59-78.

Wright, J. H. (2000). Alternative variance-ratio tests using ranks and signs. Journal of Business \& Economic Statistics, 18(1), 1-9.

\section{Note}

Note 1. For any information about the appendix, please write to the author by email: tshaalan@ taibahu.edu.sa or tharwasholan@yahoo.com 